\title{
Are interventions to promote physical activity in children a waste of time?
}

\author{
No, finding an intervention that works is essential
}

\author{
Mark Hamer principal research associate, Abigail Fisher senior research associate
}

Department of Epidemiology and Public Health, University College London, London WC1E 6BT, UK

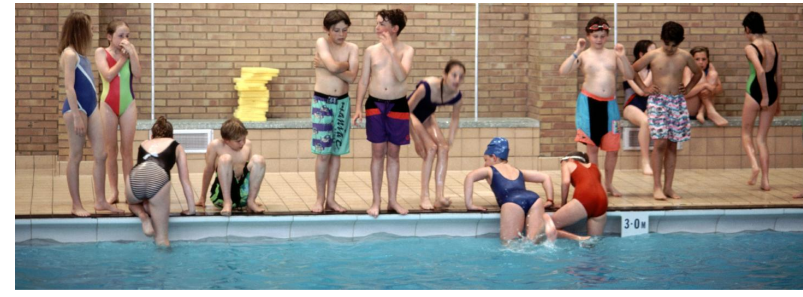

Environment impacts strongly on children's activity

[IImage: SALLY AND RICHARD GREENHILL]

Physically active children are more likely to remain active into adulthood, and maintaining a physically active lifestyle throughout life has considerable health benefits. ${ }^{1-3}$ Current UK guidelines state that all children and adolescents should engage in physical activity of moderate to vigorous intensity for at least 60 minutes a day. ${ }^{4}$ However, recent objective data from the Health Survey for England confirmed that only $33 \%$ of boys and $21 \%$ of girls currently meet those guidelines, ${ }^{5}$ and further research has shown a dramatic drop off in activity levels from childhood to adolescence. ${ }^{6}$ Thus, developing effective interventions to promote physical activity in children is crucial. In a linked research paper (doi:10.1136/bmj.e5888), Metcalf and colleagues report findings from a meta-analysis of studies that together examined 30 interventions aimed at promoting physical activity in children. ${ }^{7}$ The results indicate a small to negligible pooled effect on total time spent in physical activity, with disappointing improvements in the time spent in moderate to vigorous intensity activities (about four minutes a day). The current analysis differs from previous systematic reviews on this topic in that it considered only studies that had measured physical activity objectively using accelerometry devices. ${ }^{89}$ Accelerometers essentially provide a measure of total bodily movement across waking hours. Using this sort of objective measure is considerably different from asking people to self report discrete periods of activity over the day. In a previous systematic review that examined 57 interventions and was largely based on self reported outcomes, $47 \%$ of studies reported a significant increase in physical activity, although the effects ranged from an additional 2.6 minutes of physical education related physical activity to 283 minutes a week of overall physical activity. ${ }^{8}$ Comparing self reported physical activity and measured activity on the basis of accelerometry data is problematic. In children, in particular, accelerometers provide a more reliable and valid measurement than self reported or parent reported physical activity. Therefore, the small effects reported by Metcalf and colleagues are probably more realistic and provide the best evidence to date on the effectiveness of activity interventions in childhood. ${ }^{7}$

Accelerometry does have inherent limitations. For example, water based activities and cycling cannot be quantified; various assumptions must be made to identify non-wear periods; and the cut-off values for different intensities of activity are not clearly defined. This might partly explain the large degree of variability in effect sizes in the current analysis. An accelerometry based measure averaged over the whole day might underestimate activity taken during intervention specific periods of the day, although it could be argued that total activity over the day is the more important outcome. Indeed, one of the key strengths of this approach is that it accounts for potential displacement effects in that the intervention specific exercise sessions may simply be replacing periods of equally intense activity that would have otherwise occurred at other times of the day.

Although the present study did not examine changes in weight or body mass index as a result of the interventions, many people believe that physical inactivity is a major cause of childhood obesity. However, the evidence linking physical activity with obesity in children is weak. ${ }^{10}$ Perhaps the focus should shift away from looking at overweight and obesity as primary outcomes in physical activity interventions towards outcomes that relate to improved cardiometabolic health in children, ${ }^{1}$ regardless of their weight status.

The current review also did not consider the effects of the interventions on sedentary time, which is emerging as an important risk factor across the life course. ${ }^{111}$ Interventions that rectify the imbalance between sitting time and light intensity ("lifestyle") activity might prove to be effective in the future. 
Metcalf and colleagues' study does not provide any compelling evidence on which type of intervention might be most effective at encouraging children to engage in physical activity. Interventions in this area can be broadly broken down into home-family based or school based activities, but no differences in effect sizes were seen between these two groups in the current study. When considering interventions aimed at promoting activity in children researchers should ask themselves the following questions. Firstly, does the programme sufficiently raise activity when delivered exactly as prescribed, and, secondly, can it be effectively rolled out? Which areas should we be focusing on to make future interventions more effective? The environment has been shown to have the strongest influence on children's objectively measured activity. ${ }^{12}$ Therefore, an important area for future research is which alterations to the indoor and outdoor built environment can facilitate children's activity. This will require collaboration between physical activity researchers, built environment specialists, and policy makers. Metcalf and colleagues' study has highlighted that focused interventions to promote activity in childhood (regardless of context) have been largely unsuccessful. ${ }^{7}$ Because a wealth of evidence supports the association between an active lifestyle and many facets of child health, it is essential that successful interventions are identified. As we ride the wave of the Olympic "legacy" there has never been a better time for funders to support research from multidisciplinary teams that seek to study which sustainable environmental and policy changes result in long term increases in physical activity and reductions in sedentary time.

Competing interests: Both authors have completed the ICMJE uniform disclosure form at www.icmje.org/coi_disclosure.pdf (available on request from the corresponding author) and declare: no support from any organisation for the submitted work; no financial relationships with any organisations that might have an interest in the submitted work in the previous three years; no other relationships or activities that could appear to have influenced the submitted work.
Provenance and peer review: Commissioned; not externally peer reviewed.

1 Ekelund U, Luan J, Sherar LB, Esliger DW, Griew P, Cooper A; International Children's Accelerometry Database (ICAD) Collaborators. Moderate to vigorous physical activity and sedentary time and cardiometabolic risk factors in children and adolescents. JAMA 2012;307:704-12.

2 Sacker A, Cable N. Do adolescent leisure-time physical activities foster health and well-being in adulthood? Evidence from two British birth cohorts. Eur J Public Health 2006;16:332-6.

3 Lee IM, Shiroma EJ, Lobelo F, Puska P, Blair SN, Katzmarzyk PT; Lancet Physical Activity Series Working Group. Effect of physical inactivity on major non-communicable diseases worldwide: an analysis of burden of disease and life expectancy. Lancet 2012;380:219-29.

4 Department of Health. UK physical activity guidelines. 2011. www.dh.gov.uk/en/ Publicationsandstatistics/Publications/PublicationsPolicyAndGuidance/DH_127931.

5 Information Centre for Health and Social Care. The health survey for England-2008. Physical activity and fitness. www.ic.nhs.uk/pubs/hse08physicalactivity.

6 Nader PR, Bradley RH, Houts RM, McRitchie SL, O'Brien M. Moderate-to-vigorous physical activity from ages 9 to 15 years. JAMA 2008;300:295-305.

7 Metcalf B, Henley W, Wilkin T. Effectiveness of intervention on physical activity of children: systematic review and meta-analysis of controlled trials with objectively measured outcomes (EarlyBird 54). BMJ 2012;345:e5888.

8 Van Sluijs EM, McMinn AM, Griffin SJ. Effectiveness of interventions to promote physical activity in children and adolescents: systematic review of controlled trials. BMJ 2007;335:703.

9 Salmon J, Booth ML, Phongsavan P, Murphy N, Timperio A. Promoting physical activity participation among children and adolescents. Epidemiol Rev 2007;29:144-59.

10 Wilks DC, Sharp SJ, Ekelund U, Thompson SG, Mander AP, Turner RM, et al. Objectively measured physical activity and fat mass in children: a bias-adjusted meta-analysis of prospective studies. PLoS One 2011;6:e17205.

11 Stamatakis E, Hamer M, Mishra GD. Early adulthood television viewing and cardiometabolic risk profiles in early middle age: results from a population, prospective cohort study. Diabetologia 2012;55:311-20.

12 Fisher A, van Jaarsveld CHM, Llewellyn $\mathrm{CH}$, Wardle J. Environmental influences on children's physical activity: quantitative estimates using a twin design. PloS One 2011;5:e10110.

Cite this as: BMJ 2012;345:e6320

\section{Related links}

\section{bmj.com}

- Research: Effectiveness of interventions to promote physical activity in children and adolescents (2007;335: 703)

C BMJ Publishing Group Ltd 2012 